\title{
Assessment of Body Composition of Adult Females among Weight Managing and not Managing Groups
}

\author{
Mathur Swati and Jain Bharti* \\ Department of Food Science and Nutrition, M.D.S. University, Ajmer, India \\ *Corresponding author: Jain Bharti, Department of Food Science and Nutrition, M.D.S. University, Ajmer, India
}

\section{ARTICLE INFO}

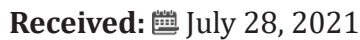

Published: 慧 August 06, 2021

Citation: Mathur Swati, Jain Bharti. Assessment of Body Composition of Adult Females among Weight Managing and not Managing Groups. Biomed J Sci \& Tech Res 37(5)-2021. BJSTR. MS.ID.006070.

Keywords: Body Composition; Adult Females; Weight Management; Bioelectrical Impedance Annalysis

\begin{abstract}
One exquisite component that marks the personality of an individual is his or her body weight. Accordingly there is a body image perception in the mind of an individual. According to the body image perception, about oneself one frames in his or her mind, the individual follows specific exercise and dietary modifications for weight management. Weight management may involve loosing weight, maintaining weight, or a desire to gain weight. Targets for managing weight may involve loosing weight, maintaining weight, or gaining weight. An individual's target for weight management may be further assessed and justified by body composition analysis. Moreover body composition analysis helps to assess the nutritional status of an individual. The present research study was a cross sectional study conducted to assess the body composition of females 18-30 years, 147 in number with reference to Body mass Index (BMI), fat mass per cent, fat free mass per cent and total body water per cent. Also a comparison of the above parameters was done among different groups of subjects namely conscious for weight but not managing weight (CNM), making attempts to loose weight (group I), making attempts to maintain weight (group II) and making attempts to gain weight (group III). An ANNOVA test was conducted to assess the difference in these parameters both within and between groups.
\end{abstract}

The results of the study revealed that the difference in BMI, fat mass per cent, fat free mass per cent was highly significant both within and between subjects of various groups, while the difference in body water per cent was found to be significant both within and between subjects of various groups. Besides this the fat mass per cent values were found to be highest in subjects of group I (loose weight), while the values were found to be lowest in subjects of group III (gain weight). The fat free mass per cent values were highest in subjects of group III (gain weight) while the values were found to be lowest among subjects of group I (loose weight). Body water is a part of fat free mass. This was confirmed since subjects in group III (gain weight) had highest quantity of total body water per cent. With reference to BMI, majority of the subjects in group I (Loose weight) fell in the Overweight or Obese category, while majority of the subjects $(66.66 \%)$ in group III (gain weight) fell into the category of being Underweight. Majority of the subjects in the conscious not managing category (48.48\%) and $73.08 \%$ subjects in group II (maintain weight) were classified as Normal. The assessment results for body composition parameters justify the weight management targets by subjects and confirm the appropriate body image perception in the individuals also.

\section{Introduction}

Human body can be understood in the form of a pyramid with 5 distinct levels. These are Chemicals, Cells, Tissues, Organs, Organ Systems [1,2]. The earliest assessment of body composition dates back to Cadaver Analysis, conducted by Clarys, Martin and
Drinkwater between 1979 and 1980 [3]. Principal components such as fat, Total body water, bone minerals, non osseous minerals and proteins have also been obtained from Cadaver Analysis [4]. The different methods employed to assess body composition are 
Cadaver Analysis, Skin fold Measurements, Body Mass Index, Total Body Water, Total Body Counting and Neutron Activation, Body Density, Dual Energy X Ray Absorptiometry, Bioelectrical Impedance Analysis Bioimpedance or biological impedance is defined as the ability of biological tissue to impede electric current [5]. Body impedance (Z) is defined as the opposition of a conductor to the flow of an alternating current, and consists of two components: Resistance (R) and Reactance (Xc) (Figure 1).
Resistance (R) is the major opposition of the conductor to the flow of electric current [6]. Reactance is an additional opposition or the storage of an electrical charge by a condenser for a short period of time; the lipid component of the membranes of the body cell mass behave as capacitors and reduce the flow of intracellular ions. In practice, Impedance is the amount of dropped voltage when a small constant current (800 micro ampere) with a fixed frequency (50 $\mathrm{kHz}$ ) passes between electrodes spanning the body [7].

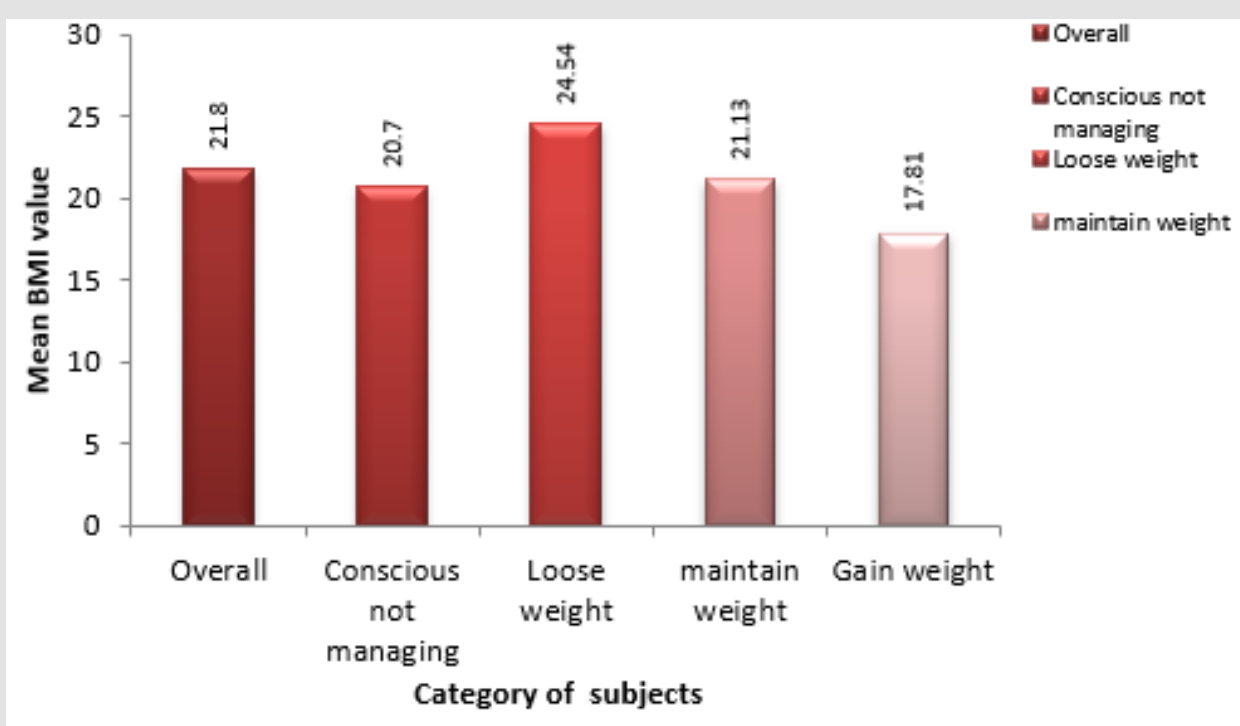

Figure 1: Mean body mass index in adult females of different categories.

\section{Objectives}

The study was framed keeping the following objectives in mind

1. To study the body composition of the adult females with reference to Body Mass Index (BMI), fat mass, fat mass per cent, fat free mass (Kg), fat free mass per cent, total body water per cent.
2. To compare the body composition parameters in different groups of adult females namely Conscious for weight but not managing weight (CNM), making attempts to loose weight (group I), making attempts to maintain weight (group II), making attempts to gain weight (group III) (Figure 2).

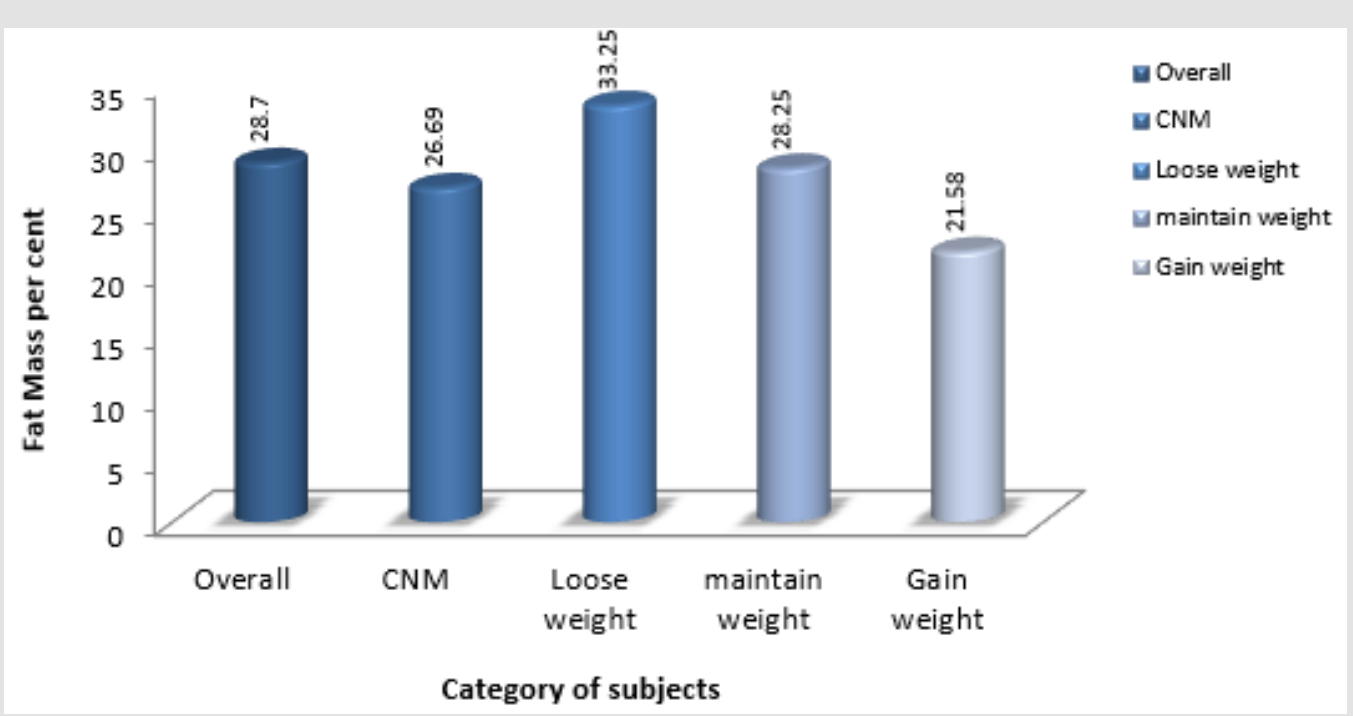

Figure 2: Mean fat Mass per cent in adult females of different categories. 


\section{Methodology}

To fulfil the objectives of the study, a sample of 147 subjects (Young females in the age group of 18 to 30 years) were selected through convenience sampling from an academic institution in the city of Ajmer. The subjects on the basis of attempts for weight management were then classified into 4 groups namely, conscious for weight, but not managing weight (CNM), making attempts to loose weight (group I), making attempts to maintain weight (group II), making attempts to gain weight (group III). The body composition analysis of the subjects was done through an automatic body composition analyser namely "Tanita BC 420 MA", operating on the principle of Bioelectrical Impedance Analysis (Figure 3). For each subject, parameters namely weight, height, Body mass index, fat mass (Kg), fat mass per cent, fat free mass (Kg), Fat free mass per cent, total body water (TBW) (Kg), and total body water per cent were measured and analysed. Subjects in different groups were expected to differ with respect to the above body composition parameters.

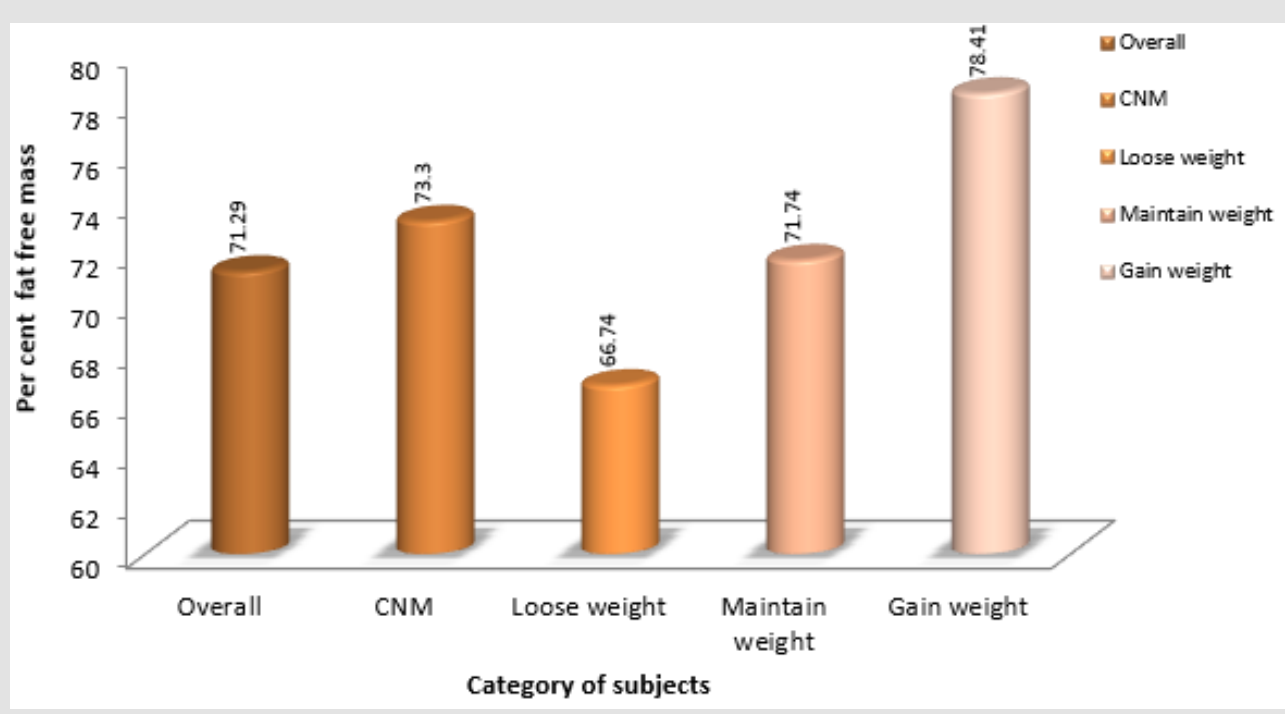

Figure 3: Mean fat Free Mass per cent in adult females of different categories.

\section{Results}

The results for the assessment of body composition parameters have been discussed below

\section{Individuals Conscious for Weight but not Managing Weight (CNM)}

This group comprised of 66 subjects who were weight conscious, but due to limitation of resources, focus on Academics and profession, limitation of time, could not make any efforts to manage weight. The results for the body composition analysis of the group "Conscious for weight but not managing weight" have been presented below

i. Age (Yrs): The mean age of the subjects was 21.01 years.

ii. Height (cm): The mean value for height was $160.42 \mathrm{~cm}$

iii. Weight (kg): The mean weight of the subjects was $53.32 \mathrm{Kg}$. iv. Fat mass per cent: The mean value for fat mass per cent was found to be 26.69 per cent.

v. Fat Mass (kg): The mean value for fat mass was found to be $14.80 \mathrm{Kg}$.

vi. Fat Free Mass (kg): The mean value for fat free mass (kg) was 38.51.

vii. Fat Free mass Per cent: The mean value for Fat free mass per cent were found to be 73.30 per cent.

viii. TBW (kg): The mean value for total body water was $26.24 \mathrm{Kg}$.

ix. TBW Per cent: The mean value for total body water per cent was 48.92

x. Body Mass Index (kg/(m)2): The mean value of Body Mass Index was found to be $20.70 \mathrm{Kg} / \mathrm{m} 2$ (Table 1). 
Table 1: Body composition parameters of subjects conscious for weight but not attempting to manage weight (CNM).

\begin{tabular}{|c|c|c|c|c|}
\hline S.No. & Body composition parameters & Mean & Range & Standard deviation \\
\hline i. & Age (years) & 21.01 & $18-30$ & 3.06 \\
\hline ii. & Height $(\mathrm{cm})$ & 160.42 & $148-172$ & 5.74 \\
\hline iii. & Weight (Kg) & 53.32 & $35.1-89.6$ & 10.20 \\
\hline iv. & Fat per cent & 26.69 & $3-46.5$ & 7.20 \\
\hline v. & Fat mass (kg) & 14.80 & $1.4-41.7$ & 6.80 \\
\hline vi. & Fat free mass $(\mathrm{kg})$ & 38.51 & $28.2-49.8$ & 4.62 \\
\hline vii. & Fat free Mass per cent & 73.30 & $61.95-97.07$ & 7.201209 \\
\hline viii. & Total Body Water (kg) & 26.24 & $19.20-37.50$ & 3.62 \\
\hline ix. & Total Body Water per cent & 48.92 & $41.9-61$ & 7.19 \\
\hline $\mathrm{x}$. & Body mass Index $\left(\mathrm{kg} /(\mathrm{m})^{2}\right)$ & 20.70 & $14.2-35$ & 3.78 \\
\hline
\end{tabular}

Body Composition Analysis of Subjects Conscious for Weight and Managing Weight (Loose Weight) (Group I)

This group comprised of 46 subjects who were weight conscious, and made different dietary modifications and exercise patterns to manage weight (Loose weight). The results for the body composition analysis of this group have been presented below

i. Age (Yrs): The mean age of the subjects was 20.86 years.

ii. Height (cm): The mean value for height of the subjects was $159.73 \mathrm{~cm}$

iii. Weight (kg): The mean weight of the subjects was $62.99 \mathrm{Kg}$.

iv. Fat mass per cent: The mean fat mass per cent value was 33.25 per cent.

v. Fat Mass (kg): The mean fat mass value was $21.77 \mathrm{~kg}$ vi. Fat Free Mass (kg): The mean value of fat free mass was calculated to be $41.22 \mathrm{Kg}$

vii. Fat Free mass per cent: The fat free mass values obtained in kilogram when converted into percentage showed a mean of 66.74 per cent.

viii. TBW (kg): The mean value of the total body water in Kilogram was $29.18 \mathrm{Kg}$.

ix. TBW Per cent: The mean value for the total body water percentage was 46.89. This indicated that the subjects were normal with respect to body water percentage, but were on the lower margin, since a body water content of 45 to $60 \%$ is considered normal for females.

x. Body Mass Index $\left(\mathrm{kg} /(\mathbf{m})^{2}\right)$ : The mean value for Body mass Index was found to be $24.54 \mathrm{Kg} / \mathrm{m} 2$ (Table 2).

Table 2: Body composition parameters of subjects conscious for weight and managing weight (loose weight).

\begin{tabular}{|c|c|c|c|}
\hline S.No. & Body composition parameters & Mean & Range \\
\hline i. & Age (years) & 20.86 & $18-30$ \\
\hline ii. & Height (cm) & 159.73 & $150-176$ \\
\hline iii. & Weight (Kg) & 62.99 & $42.5-101.6$ \\
\hline iv. & Fat mass (Kg) & 21.77 & $8.5-49$ \\
\hline v. & Fat mass per cent & 33.25 & $14.94-49.2$ \\
\hline vi. & Fat free mass & 41.22 & $32.3-56.8$ \\
\hline vii. & Fat free Mass per cent & 66.74 & $50.75-79.20$ \\
\hline viii. & Total Body Water (Kg) & 29.18 & $22-43.5$ \\
\hline ix. & Total Body Water Per Cent & 46.89 & 4.95 \\
\hline x. & Body mass Index (kg/(m)2) & 24.54 & $40.2-53.4$ \\
\hline
\end{tabular}

Body Composition Analysis of Subjects Conscious for Weight and Managing Weight (Maintain Weight) (GROUP II)

This group comprised of 26 subjects who were weight conscious, and made different dietary modifications and exercise patterns to manage weight (Maintain weight). The results for the body composition analysis of this group have been presented below

i. $\quad$ Age (Yrs): The mean age of the subjects was 22.15 years

ii. Height (cm): The average height of the subjects was 160.92 $\mathrm{cm}$ 
iii. Weight (kg): The average value of weight for the subjects comprising this particular group was $54.69 \mathrm{~kg}$

iv. Fat mass per cent: The values of fat mass when converted into percentage, demonstrated a mean value of 28.25 per cent.

v. Fat Mass (kg): Fat mass values exhibited an average value of $15.63 \mathrm{~kg}$.

vi. Fat Free Mass (kg): The mean value of fat free mass was 39.06 $\mathrm{Kg}$.

vii. Fat Free mass Per cent: The fat free mass values so obtained when converted to percentage, exhibited a mean value of 71.74 .

viii. TBW (kg): The average value for the total body water content in kilogram was $26.62 \mathrm{Kg}$.

ix. TBW Per cent: A mean value of 48.84 was obtained for the total body water percentage values. The mean value indicated that the subjects could be categorised as normal with respect to body water percentage.

x. Body Mass Index $(\mathrm{kg} /(\mathrm{m}) 2)$ : The mean value of BMI for the subjects was $21.13 \mathrm{Kg} /(\mathrm{m}) 2$ (Table 3$)$.

Table 3: Body composition parameters of subjects conscious for weight and managing weight (maintain weight).

\begin{tabular}{|c|c|c|c|}
\hline S.No. & Body composition parameters & Mean & Range \\
\hline i. & Age (years) & 22.15 & $18-30$ \\
\hline ii. & Height (cm) & 160.92 & $141-172$ \\
\hline iii. & Weight (Kg) & 54.69 & $42.6-71.9$ \\
\hline iv. & Fat mass (kg) & 15.63 & $10.5-28.8$ \\
\hline v. & Fat mass per cent & 28.25 & $20.9-40$ \\
\hline vi. & Fat free mass (Kg) & 39.06 & $29.7-48.4$ \\
\hline vii. & Fat free Mass per cent & 71.74 & $59.94-79.08$ \\
\hline viii. & Total Body Water (Kg) & 26.62 & $21.2-35$ \\
\hline ix. & Total Body Water Per Cent & 48.84 & 2.81 \\
\hline x. & Body mass Index (Kg/(m) & 2.75 & $2.7-55.1$ \\
\hline
\end{tabular}

\section{Body Composition Analysis of Subjects Conscious for Weight and Managing Weight (Gain weight) (GROUP III)}

This group comprised of 9 subjects who were weight conscious, and made different dietary modifications and exercise patterns to manage weight (Gain weight). The results for the body composition analysis of this group have been presented below

i. Age (Yrs): The mean age of the subjects was 20.88 years.

ii. Height (cm): The mean value of height for the subjects was $159.22 \mathrm{~cm}$.

iii. Weight (kg): The mean weight of the subjects was $45.07 \mathrm{Kg}$.

iv. Fat mass per cent: The obtained average value for fat mass per cent was 21.58 .

v. Fat Mass (kg): The calculated mean value for fat mass was

\section{$9.81 \mathrm{Kg}$}

vi. Fat Free Mass (kg): The mean value of fat free mass was 35.26 $\mathrm{Kg}$.

vii. Fat Free mass Per cent: The average fat free mass per cent value was calculated to be 78.41 .

viii. TBW (kg): The total body water values exhibited a mean of $23.7 \mathrm{Kg}$.

ix. TBW per cent: The mean value for total body water per cent was found to be 52.64. Thus the subjects could be classified as normal with respect to the body water compartment.

x. Body Mass Index $(\mathrm{kg} /(\mathrm{m}) 2)$ : The mean value of BMI measurements taken for the subjects in the group was found to be $17.81 \mathrm{Kg} /(\mathrm{m})^{2}$ (Tables 4 \& 5).

Table 4: Body composition of subjects conscious for weight and managing weight (gain weight).

\begin{tabular}{|c|c|c|c|}
\hline S.No. & Body composition parameters & Mean & Range \\
\hline i. & Age (years) & 20.88 & $18-24$ \\
\hline ii. & Height (cm) & 159.22 & $150-167$ \\
\hline iii. & Weight (Kg) & 45.07 & $35.2-49.4$ \\
\hline iv. & Fat mass per cent & 21.58 & $17.1-29.5$ \\
\hline v. & Fat mass (kg) & 9.81 & $6-14.5$ \\
\hline
\end{tabular}




\begin{tabular}{|c|c|c|c|}
\hline vi. & Fat free mass $(\mathrm{kg})$ & 35.26 & $29.2-39.6$ \\
\hline vii. & Fat free Mass per cent & 78.41 & $70.46-82.95$ \\
\hline viii. & Total Body Water $(\mathrm{kg})$ & 23.7 & $19.4-26.7$ \\
\hline ix. & Total Body Water Per Cent & 52.64 & $49.7-55.1$ \\
\hline x. & Body mass Index $\left(\mathrm{Kg} /(\mathrm{m})^{2}\right)$ & 17.81 & 1.83 \\
\hline
\end{tabular}

Table 5: Mean \pm Standard Deviation of body composition parameters in different groups of subjects (18-30 years).

\begin{tabular}{|c|c|c|c|c|c|c|c|}
\hline No. & $\begin{array}{c}\text { Body composition } \\
\text { parameter }\end{array}$ & $\begin{array}{c}\text { Not attempting } \\
\text { for weight } \\
\text { management }\end{array}$ & $\begin{array}{c}\text { Group I } \\
\text { Loose weight }\end{array}$ & $\begin{array}{c}\text { Group II } \\
\text { Maintain } \\
\text { weight }\end{array}$ & $\begin{array}{c}\text { Group III } \\
\text { Gain weight }\end{array}$ & F ratio & P value \\
\hline 1 & BMI & $20.70 \pm 3.78$ & $24.54 \pm 34.58$ & $21.13 \pm 2.43$ & $17.81 \pm 2.02$ & $13.45^{* * *}$ & $\mathrm{P}<0.001$ \\
\hline 2 & Fat mass $\%$ & $26.69 \pm 7.20$ & $33.25 \pm 6.47$ & $28.25 \pm 4.47$ & $21.58 \pm 3.58$ & $13.65^{* * *}$ & $\mathrm{P}<0.001$ \\
\hline 3 & Fat free mass $\%$ & $73.30 \pm 7.20$ & $66.74 \pm 6.47$ & $71.74 \pm 4.47$ & $78.41 \pm 3.61$ & $13.67^{* * *}$ & $\mathrm{P}<0.001$ \\
\hline 4 & Total body water $\%$ & $48.92 \pm 7.19$ & $46.89 \pm 2.99$ & $48.84 \pm 2.75$ & $52.64 \pm 1.83$ & $3.44^{*}$ & $\mathrm{P}<0.05$ \\
\hline
\end{tabular}

BMI is the one of the most important and basic parameter that helps in the assessment of nutritional status. Therefore a study of the distribution of the subjects in various BMI categories was done, the results of which have been presented below:

1) Conscious for Weight, but not Managing Weight (CNM): Employing the BMI criteria, 21 subjects (31.82\%) could be classified as Underweight, 32 (48.48\%) as Normal, 5 (7.58\%) as Overweight and $8(12.12 \%)$ as Obese. Thus majority of the subjects fell in the "Normal" category.

2) Loose Weight (Group I): Employing the BMI criteria, 3 subjects $(6.52 \%)$ could be classified as underweight, $16(34.78 \%)$ as Normal, $12(26.08 \%)$ as Overweight and $15(32.60 \%)$ as Obese. Thus majority of the subjects fell either into the "Overweight or Obese category".

3) Maintain Weight (Group II): Employing the BMI criteria, $2(7.69 \%)$ subjects could be classified as Underweight, 19 (73.08\%) as Normal, 3 (11.54\%) as Overweight and 2 (7.69\%) as Obese. Thus majority of the subjects were "Normal" with respect to BMI.

4) Gain Weight (Group III): With respect to BMI 3 (33.33\%) subjects could be classified as "Normal", while, majority that is 6 subjects $(66.66 \%)$ were classified as "Underweight". This clearly shows that majority of the subjects fell into the "Underweight" category.

A statistical analysis using SPSS was done to assess significance difference in the body composition parameters of different groups. The difference in the BMI was highly significant $(\mathrm{P}<0.001)$ both within and between subjects of various categories Conscious not managing (CNM), loose weight (Group I), maintain weight (group II), gain weight (group III). The difference in fat mass per cent was highly significant $(\mathrm{P}<0.001)$ both within and between subjects of various categories (Conscious not managing (CNM), loose weight
(Group I), maintain weight (group II), gain weight (group III). The difference in fat free mass per cent was highly significant $(\mathrm{P}<0.001)$ both within and between subjects of various categories (Conscious not managing (CNM), loose weight (Group I), maintain weight (group II), gain weight (group III). The difference in body water per cent was significant $(\mathrm{P}<0.05)$ both within and between subjects of various categories Conscious not managing (CNM), loose weight (Group I), maintain weight (group II), gain weight (group III).

\section{Summary and Conclusion}

In reference to BMI it was seen that majority of the subjects falling in group I (Loose weight) fell in the Overweight and Obese category. Alternately subjects falling in group III (gain weight) were found to be "Underweight". Lastly majority of the subjects falling in the conscious not managing group (CNM) and in group II (maintain weight) fell in the Normal category. The fat mass per cent values were found to be highest in subjects of group I lloose weight), while the values were found to be lowest in subjects of group III (gain weight). The above results justify the attempts of the subjects falling in group I and group III to loose and gain weight respectively. The fat free mass per cent was found to be highest in subjects of group III (gain weight), while the values were found to be lowest among subjects of group I (Loose weight). Since subjects falling in group III (gain weight), had highest quantity of fat free mass they similarly possessed highest quantity of total body water per cent. The category wise BMI distribution of the subjects, along with the above parameters simultaneously justifies the weight management objective of the subjects. Many a times females may have an inappropriate body image perception which may make them frame incorrect objective for weight management. As such it can also be said that the subjects in the present study, had an appropriate body image perception. But the practices employed for weight management should be absolutely healthy so that along with weight management, an optimum Nutritional Status can be achieved. 


\section{References}

1. Ellis K (1996) Whole-body counting and neutron activation analysis In: Roche A, Heymsfield S, Lohman T (Eds.)., Human body composition. Champaign, IL: Human Kinetics Press, pp 45-61.

2. Wang ZM, Pierson RN, Heymsfield SB (1992) The five level model a new approach to organising body composition research. Am J Clin Nutr 56(1): 19-28.

3. Clarys JP, Martin AD, Drinkwater DT (1984) Gross tissue weights in the human body by Cadaver dissection. Hum Biol 56(3): 459-473.

\section{ISSN: 2574-1241}

DOI: 10.26717/BJSTR.2021.37.006070

Jain Bharti. Biomed J Sci \& Tech Res

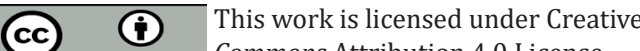

Submission Link: https://biomedres.us/submit-manuscript.php
4. Henche SA, Pellico LG (2005) Body composition evaluation methods. Eur J Anat 9(2): 117-124.

5. Martinsen OG, Grimne S (2011) Bioimpedance and Bioelectricity Basics ( $2^{\text {nd }}$ Edn.)., Academic Press: Waltham, MA, USA.

6. Kotler DP, Burastero S, Wang J, Pierson R (1996) Prediction of body cell mass, fat free mass, and total body water with bioelectrical impedance analysis. effects of race, sex, and disease. Am J Clin Nutr 64(3): 489S497S.

7. Pietrobelli A, Heymsfield SB (2002) Establishing body composition in obesity. J Endocrinol Invest 25: 884-892.

$\begin{array}{ll}\text { BIOMEDICAL } & \text { Assets of Publishing with us } \\ \text { RESEARCHES } & \text { - Global archiving of articles } \\ \text { - Immediate, unrestricted online access } & \text { - Rigorous Peer Review Process } \\ & \text { - Authors Retain Copyrights } \\ & \end{array}$

